\title{
Consumer knowledge and practices to pork safety in two Taenia solium cysticercosis endemic districts in Eastern Cape Province of South Africa
}

\author{
Msawenkosi I. Sithole ${ }^{1 *}$, Johan L. Bekker ${ }^{1}$ and Samson Mukaratirwa ${ }^{2}$
}

\begin{abstract}
Background: Globally, Taenia solium can cause cysticercosis in humans (including neurocysticercosis) and in pigs through ingestion of eggs and taeniasis in humans through ingestion of raw/undercooked pork contaminated with mature cysts. It is now recognised globally as one of the most prevalent food-borne parasitic diseases. The majority of cases have been reported in developing countries where consumption of food produced under unhygienic conditions is prevalent, exacerbated by lack of food safety education. The aim of this study was to determine the knowledge and practices of consumers towards pork safety in two districts of the Eastern Cape Province of South Africa, where T. solium cysticercosis is endemic in pigs and humans.
\end{abstract}

Methods: Three-hundred-and-sixty-one (361) participants were conveniently interviewed on consumer knowledge (harmfulness of T. solium cysticercosis, ability to identify cysts, trustworthiness of registered butcheries and legal requirements) and practices (storage of pork and method(s) of cooking pork safely) through a structured questionnaire. Chi-square for association of variables was used to compare differences in the districts.

Results: Overall, $73.1 \%$ of the study group from both districts agreed that pork forms an important part of their diet. Consumers (54.2\%: 189/349) agreed that pork infected with T. solium cysts could be harmful, and 57.3\% (188/328) indicated their inability to identify T. solium cysts in pork when slaughtered at home. Although $69.5 \%$ (234/352) trusted pork bought from butcheries, only 52.2\% (187/358) were aware that butcheries must present a registration certificate in order to operate. This coincides with the fact that very few $(<10 \%)$ were aware of the legal requirements in terms of disease control, slaughter and food preparation. Most consumers (88.7\%: 268/302) kept pork in the fridge and only $11.3 \%(34 / 302)$ kept it in a freezer $(p=0.02)$. Although not significantly different between the districts $(p=0.15)$, consumers in Alfred Nzo (71.4\%: 152/213) and OR Tambo (61.2\%: 74/12) mostly cooked pork as a stew, followed by braai/barbeque and frying or baking. This was in line with the fact that consumers in Alfred Nzo (79\%: 147/186) and OR Tambo (80.8\%: 120) preferred well-cooked pork; the main reason for this was the belief that cooking kills germs (43.6\%: 121/277) followed by rendering the meat tasty (26.4\%: 73/277).

\footnotetext{
*Correspondence: MsawenkosiS@daff.gov.za

'Department of Environmental Health, Tshwane University of Technology,

Pretoria 0001, South Africa

Full list of author information is available at the end of the article
}

(c) The Author(s). 2020 Open Access This article is distributed under the terms of the Creative Commons Attribution 4.0 International License (http://creativecommons.org/licenses/by/4.0/), which permits unrestricted use, distribution, and reproduction in any medium, provided you give appropriate credit to the original author(s) and the source, provide a link to the Creative Commons license, and indicate if changes were made. The Creative Commons Public Domain Dedication waiver (http://creativecommons.org/publicdomain/zero/1.0/) applies to the data made available in this article, unless otherwise stated. 


\begin{abstract}
(Continued from previous page)
Conclusions: Consumers surveyed in the two districts were somewhat aware that T. solium cysticercosis could be harmful, although some were not able to identify T. solium cysts in pork. They also lacked sufficient knowledge regarding butchery certification and other legal requirements related to disease control, slaughter and food preparation. Practices related to cooking have the potential to promote the transmission of human taeniasis and the fact that most respondents preferred stewed pork could be a positive sign, as the cysts are destroyed during the cooking process. Results from this study are useful for the development of a control and prevention strategy targeted towards consumers, and the creation of awareness of food safety, with special emphasis on $T$, solium cysticercosis.
\end{abstract}

Keywords: Taenia solium cysticercosis, Food/meat safety, Consumer knowledge and practices

\section{Background}

Food-borne diseases have become widespread and are a serious public health problem, especially in industrialised countries where the percentage of people infected by food-borne diseases each year has been increasing [1]. This has been attributed to industrialisation of animal production, mass food processing and distribution, globalisation of the food trade and increased mobility of people and goods around the world [1, 2]. Food-borne parasitic diseases result in considerable morbidity and mortality [3], and T. solium is among the list of foodborne zoonotic parasites known to cause epilepsy and other neurological sequelae in populations across subSaharan Africa [3]. When pig (intermediate host) ingests faeces contaminated with $T$. solium eggs, larvae invade the body of the animal, mostly in the subcutaneous fat, muscles or brain, resulting in porcine cysticercosis. When human (definitive host) ingests infected (metacestode) in under-cooked or raw pork this develops to mature form of the tapeworm, causing taeniasis. Humans occasionally become intermediate hosts by drinking water or eating food contaminated with $T$. solium eggs or by transferring eggs to mouth with contaminated hands or through autoinfection. This may result in human cysticercosis and/or neurocysticercosis. Taenia solium cysticercosis is an underreported and neglected zoonotic disease in man and pigs in many developing countries [4] and has been classified as one of the most important global foodborne parasites [5]. The public health and economic impacts are difficult to determine because of the complexities of the disease in resource-poor livestock farming and the economic loss due to meat condemnation (lack of affordable diagnostic tools in humans, ineffectiveness of meat inspection in detecting cysts, home slaughter of pigs and stigma related to NCC in endemic areas) [6-8]. In South Africa, the diseases' cost was estimated to be USD 5 million for the agricultural sector alone, with an overall cost of between USD 18.6 million and USD 34.2 million [6].

Despite strong evidence indicating that $T$. solium is an important pathogen of resource-poor, pig farming communities in South Africa, there has been only one report on the prevalence of porcine cysticercosis of $64.6 \%$ in the villages of Alfred Nzo and OR Tambo Districts of the Eastern Cape Province, South Africa [9]. However in the past 30 years, several hospital surveys utilising serological and/or radiological diagnostic techniques have indicated that $28-50 \%$ of epileptic cases including children were positive for cysticercosis [10]. Inactive and active NCC detected through computed tomography CT scans were found in $61.1 \%$ of patients with epilepsy in Lusikisiki, in the Alfred Nzo District of South Africa [11].

South Africa has the largest number of pigs in subSaharan Africa, of which approximately 25\% are free ranging and owned by emerging pig producers in resource-poor areas of the country $[9,12]$. As part of this study, Sithole et al. [13] reported on pig husbandry practices, pig health management, feeding, marketing and slaughter of pigs by farmers in two districts of Eastern Cape Province, South Africa. Results showed that pigs were managed under traditional free range, resulting in them roaming freely with other domestic animals such as cattle, sheep, goats, chickens, dogs and game.

Although meat inspection has traditionally been the main means of control to detect cysts at slaughter, the effectiveness of the method is poor and has some limitations in terms of sensitivity [14, 15]. Sithole et al. [16] also confirmed that meat inspection alone was insufficient to detect porcine cysticercosis and therefore suggested additional multiple incisions on the heart, tongue, shank and masticatory muscles to improve cyst detection.

Although studies on T. solium cysticercosis have been conducted in Alfred Nzo and OR Tambo Districts [12, 17] no study has been carried out on consumer knowledge and practices on pork safety. The objective of this study therefore was to assess consumer knowledge and practices of pork safety in two T. solium cysticercosis endemic districts in Eastern Cape Province, South Africa.

\section{Methods}

\section{Study areas}

The study was conducted in villages located in two district municipalities of Eastern Cape Province, namely Alfred Nzo and O.R. Tambo Districts and the 
demographic characteristics and prevalence of $T$. solium taeniasis/cysticerosis in the two locations have been previously described [17].

\section{Study design}

This study forms part of a larger study related to the occurrence and detection of T. solium in Eastern Cape Province of South Africa. A cross-sectional communitybased study was conducted between August and October 2016. Prior to commencement of the survey, an inception meeting was held with the representatives of the local House of Traditional Leaders to explain the purpose of the study. Convenience sampling, which is a non-probability sampling technique, was used to select respondents based on their accessibility and willingness to participate in the study.

Three-hundred-and-sixty-one (361) household heads, originating from 30 villages of Alfred Nzo $(n=236)$ and OR Tambo $(n=125)$ districts were included. A structured questionnaire collected information from consumers on demographics (age, gender, level of education), consumer knowledge (knowledge of T. solium cysticercosis, ability to identify cysts, trustworthiness of butcheries and legal requirements) and practices (storage, methods of cooking) towards pork safety. The questionnaire was translated into IsiXhosa, which is the native language of both the study districts and was pre-tested with five consumers per district and improvements were made prior to the administration to study participants. The pre-tested questionnaires were not included in the results. Due to the high level of illiteracy among villagers, interviews, with the aid of the translated structured questionnaire, were conducted by the researcher and a research assistant both of whom were conversant with IsiXhosa. In South Africa, persons under 18 years of age are regarded as minors therefore, no such person was interviewed during the study.

\section{Data analysis}

Due to the nature of the questions, not all were answered by respondents and therefore the sample size (n) of the variables differed. Frequencies observed within the categories of each question and between districts were tested by constructing row $\mathrm{x}$ column frequency tables of meaningful associations and a Chi-square $\left(x^{2}\right)$ test for independence (association) of variables $(p \leq 0.05$ at $95 \%$ CL were regarded as significantly different) [18]. All data analyses were done using SAS Statistical Software [19].

\section{Results}

In total, 361 questionnaires were completed, of which 65.4\% (236) were from Alfred Nzo and 34.6\% (125) from OR Tambo district $(p=0.03)$. Overall, $73.1 \%$ of the respondents from the two districts confirmed that pork formed an important part of their diet.
Socio-demographic information of the study districts

Table 1 shows the socio-demographic characteristics of respondents from the two study districts. Gender distribution between the two districts differed significantly $(p=0.03)$, with most respondents being males $(56.2 \%$ : 203/361). Of the $296(n=358)$ from both districts who indicated that they purchase meat themselves, $56 \%$ were males. The age distribution of respondents from the two districts was significantly different $\left(\chi^{2}(\mathrm{df}=5) 50.0 ; p=\right.$ 0.01 ), with a mean age of 45 years (range $=18-88$ years) for Alfred Nzo, and 34 years (range $=18-80$ years) for OR Tambo. The number of family members per household for both districts ranged from one to five, with a mean of three $\left(\chi^{2}(\mathrm{df}=4) 7.3 ; p=0.11\right)$. A higher rate of unemployment $\left(X^{2}(\mathrm{df}=4) 31.6 ; p=0.01\right)$ was observed in OR Tambo (47.2\%: 58/123) than in Alfred Nzo (29.8\%: 70/235). A high number of respondents in both Alfred Nzo (50.0\%: 118/236) and OR Tambo (43.2\%: 54/125) had an education $\left(\mathrm{X}^{2}(\mathrm{df}=3) 4.7 ; p=0.19\right)$ below grade 9 .

\section{Consumer knowledge}

Table 2 shows $54.2 \%(n=349)$ of the consumers in Alfred Nzo $(n=110 / 228)$ and OR Tambo $(n=79 / 121)(p=0.01)$ expressed that pork with cysticercosis may be harmful to their health. Furthermore, 42.7\% $(n=328)$ in Alfred Nzo $(95 / 211)$ and OR Tambo (45/117) indicated they could identify cysts when they slaughtered pigs at home, and in IsiXhosa (native language) referred to it as "Amaqhakuva, Amaqhanqa or Intshulube". It was unclear if they knew what measly pork looked like, as many respondents verbally indicated they could not distinguish between a piece of fat or a cyst. Majority of consumers were not aware of the symptoms related to human cysticercosis. In Alfred Nzo, 39.8\% (140/227) trusted pork purchased from local butcheries compared to OR Tambo, where only $26.7 \%(94 / 125)$ trusted such pork $(p=0.01)$. In Alfred Nzo, 68.6\% (131/191) of respondents and 70.9\% (88/124) from O.R. Tambo believed butcheries were inspected on a regular basis for food hygiene $(p=0.65)$. Only $48.2 \%(113 /$ $234)$ in Alfred Nzo and 59.7\% (74/124) in OR Tambo were aware that butcheries must have a registration certificate $(p=0.04)$ in order to operate. Generally, consumers lacked knowledge regarding existing meat/food safety legislations as they are not aware of the existence of legislation, such as the Animal Disease Act (90.8\%: 277/305) $(p=0.01)$, Meat Safety Act (90.0\%: 276/307) $(p=0.01)$, Foodstuff, Cosmetics and Disinfectant Act (91.1\%: 266/ 292) $(p=0.01)$ and National Health Act (89.5\%: 273/305) $(p=0.01)$.

\section{Consumer practices}

A summary of the respondents' practices on pork preparations and consumptions is shown in Table 3. Most respondents in the two districts (88.7\%: 268/302) stored 
Table 1 Demographic characteristics of respondents on pork safety from Alfred Nzo and OR Tambo Districts in Eastern Cape Province of South Africa

\begin{tabular}{|c|c|c|c|c|c|}
\hline Factor & Number of respondents & Alfred Nzo District $(n=236)$ & OR Tambo District $(n=125)$ & $x^{2}$ & $P$-value \\
\hline Gender & 361 & & & 4.69 & 0.03 \\
\hline Male & & $123(52.1 \%)$ & $80(64.0 \%)$ & & \\
\hline Female & & $113(47.9 \%)$ & 45 (36.0\%) & & \\
\hline Age Group & 361 & & & 50.00 & 0.01 \\
\hline$\leq 24$ & & $19(8.1 \%)$ & $36(28.8 \%)$ & & \\
\hline $25-34$ & & $48(20.3 \%)$ & $31(24.8 \%)$ & & \\
\hline $35-44$ & & $43(18.2 \%)$ & $21(16.8 \%)$ & & \\
\hline $45-54$ & & $56(23.7 \%)$ & $23(18.4 \%)$ & & \\
\hline $55-64$ & & $37(15.7 \%)$ & $9(7.2 \%)$ & & \\
\hline$>64$ & & $33(14.0 \%)$ & $5(4.0 \%)$ & & \\
\hline Mean & & 45 years & 34 years & & \\
\hline Members in a household & 361 & & & 7.33 & 0.12 \\
\hline$\leq 2$ & & $14(6.0 \%)$ & $10(8.0 \%)$ & & \\
\hline $3-5$ & & $84(35.6 \%)$ & $30(24.0 \%)$ & & \\
\hline $6-8$ & & $83(35.2 \%)$ & $56(44.8 \%)$ & & \\
\hline $9-11$ & & $32(13.6 \%)$ & $13(10.4 \%)$ & & \\
\hline$>11$ & & $23(9.8 \%)$ & $16(12.8 \%)$ & & \\
\hline Mean & & 3 & 3 & & \\
\hline Source of income & 358 & & & 31.59 & 0.01 \\
\hline Work & & $41(17.5 \%)$ & $21(17.1 \%)$ & & \\
\hline Self-employed & & 72 (30.6\%) & 11 (8.9\%) & & \\
\hline Grants & & $24(10.2 \%)$ & 25 (20.3\%) & & \\
\hline Pension & & $28(11.9 \%)$ & $8(6.5 \%)$ & & \\
\hline Unemployed & & 70 (29.8\%) & $58(47.2 \%)$ & & \\
\hline Education & 361 & & & 4.72 & 0.19 \\
\hline No education & & $22(9.3 \%)$ & $9(7.2 \%)$ & & \\
\hline Grades 1-8 & & $118(50.0 \%)$ & $54(43.2 \%)$ & & \\
\hline Grades 9-12 & & 90 (38.1\%) & 61 (48.8\%) & & \\
\hline Tertiary level & & $6(2.5 \%)$ & $1(0.8 \%)$ & & \\
\hline
\end{tabular}

Note: $p<0.05$ denote significant difference between the Alfred Nzo and OR Tambo Districts

their pork in a fridge, while only a small number (11.3\%: 34/302) used freezers $\left(\chi^{2}(\mathbf{d f}=\mathbf{1}) 5.0 ; p=0.05\right)$. The majority of respondents from both districts (67.7\%: 226/334) preferred the traditional cooking method of stew compared to braai (barbecue) (30.2\%: 95/334), frying (2.5\%: 9/334) and baking (1\%: 4/334) $\left(\chi^{2}(\mathbf{d f}=4) 6.7 ; p=0.15\right)$. Most respondents of the two districts (79.9\%: 244/306) who preferred pork to be cooked well (well done) $\left(X^{2}(\mathbf{d f}=3) 2.6 ; p=0.45\right) ; 42.9 \%$ (121/277) indicated the main reason for "well done" cooking was that it killed germs $\left(X_{(\mathbf{d f}=4)}^{2} 7.5 ; p=0.11\right)$.

\section{Discussion}

There is a strong relationship between consumer perception of risks, trust in food safety and purchasing behaviour [20]. This study revealed that there were more men responsible for meat purchasing compared to women, which was an interesting phenomenon. In most African cultural practices, it is the responsibility of women to buy and cook food for the family [21], as women tend to be more aware of food safety than men [22]. In this case, a possible intervention would be to establish educational food safety programmes specifically for food handlers. The high level of unemployment was comparable to that of previous studies (approximately $55 \%)$ in the area $[9,23]$ and this compels people to buy pork and other meat from cheap informal/illegal food vendors, or to slaughter animals themselves for own consumption and commercial purposes to enhance income [24]. Of concern was that a high percentage of 


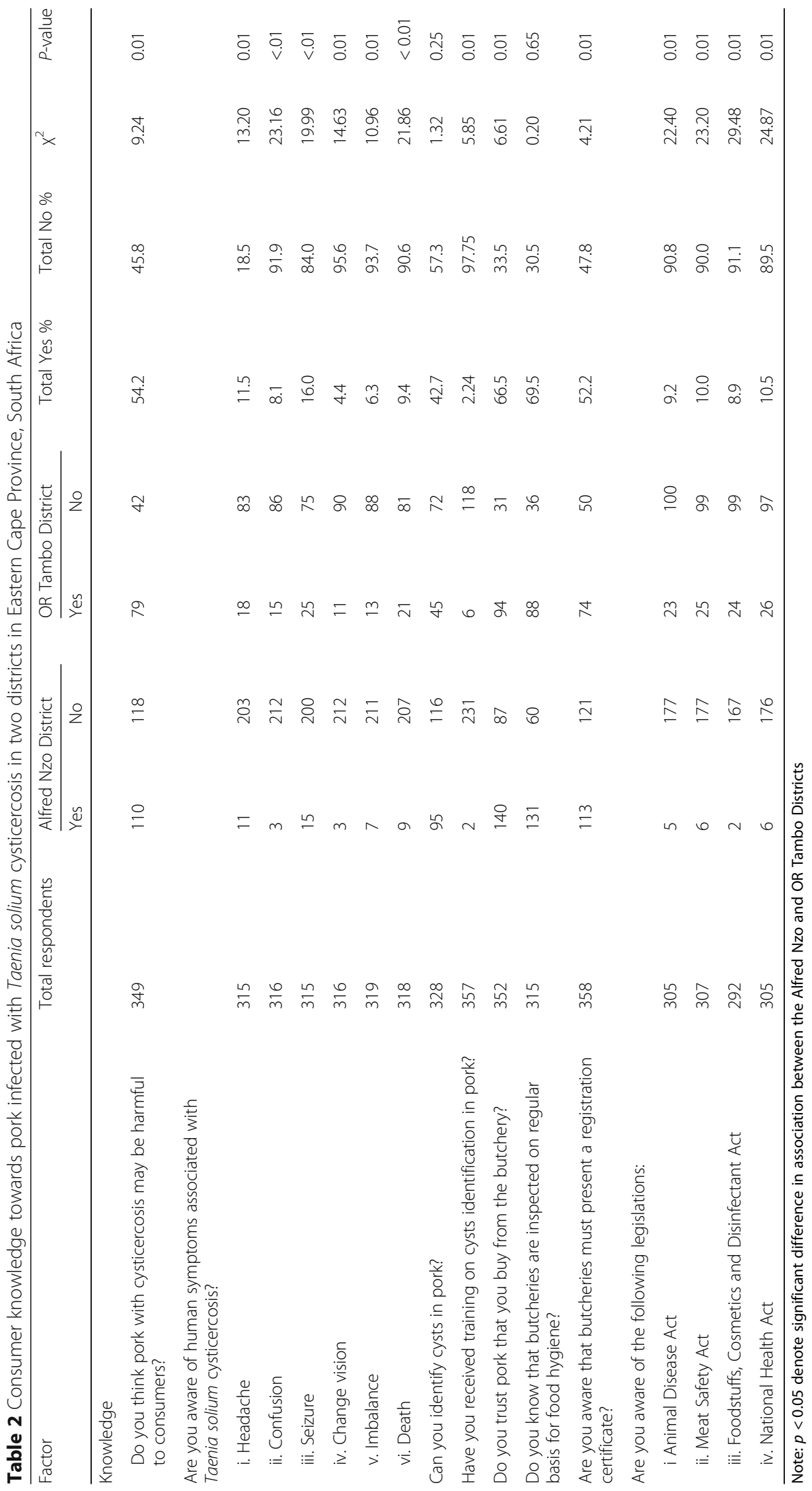


Table 3 Consumer practices in cooking and consumption of pork in two districts endemic for Taenia solium cysticercosis in Eastern Cape Province, South Africa

\begin{tabular}{|c|c|c|c|c|c|}
\hline Factor & Number of respondents & Alfred Nzo District & OR Tambo District & $x^{2}$ & $P$-value \\
\hline Where do you keep your pork after slaughter/buying? & 302 & & & 5.03 & 0.05 \\
\hline Fridge & & $151(85.3 \%)$ & $117(93.6 \%)$ & & \\
\hline Freezer & & $26(14.7 \%)$ & $8(6.4 \%)$ & & \\
\hline How do you cook your pork? & 334 & & & 6.72 & 0.15 \\
\hline Stew & & $152(71.4 \%)$ & $74(61.2 \%)$ & & \\
\hline Braai & & $51(23.9 \%)$ & $44(36.4 \%)$ & & \\
\hline Fry in oil or fat & & $7(3.3 \%)$ & $2(1.7 \%)$ & & \\
\hline Bake in oven & & $2(0.9 \%)$ & $1(0.7 \%)$ & & \\
\hline Other (unspecified) & & $1(0.5 \%)$ & $0(0.0 \%)$ & & \\
\hline How do you prefer to eat your pork? & 306 & & & 2.62 & 0.45 \\
\hline Well done & & $147(79 \%)$ & $97(80.8 \%)$ & & \\
\hline Medium to well-done & & $27(14.5 \%)$ & $15(12.5 \%)$ & & \\
\hline Medium to rare & & $9(4.9 \%)$ & $8(6.7 \%)$ & & \\
\hline Rare & & $3(1.6 \%)$ & $0(0.0 \%)$ & & \\
\hline What is the reason you want your pork to be cooked this way? & 277 & & & 7.54 & 0.11 \\
\hline Kill gems & & $77(47.9 \%)$ & $44(37.9 \%)$ & & \\
\hline Tasty & & $42(26.1 \%)$ & $31(26.8 \%)$ & & \\
\hline Stop blood & & $21(13 \%)$ & $28(24.1 \%)$ & & \\
\hline Soft & & $19(11.8 \%)$ & $10(8.6 \%)$ & & \\
\hline Tender & & $2(1.2 \%)$ & $3(2.6 \%)$ & & \\
\hline
\end{tabular}

Note: $p<0.05$ denote significant difference in association between the Alfred Nzo and OR Tambo Districts

consumers had an education level below grade 9, which is the minimum school education level in South Africa [25]. This result is similar to that of other reports in Alfred Nzo, where $58 \%$ of respondents were without formal education [26] and OR Tambo had 26\% with no schooling at all [27].

It has been reported that a low level of education exacerbates a high unemployment rate [25, 28, 29], and this may impact negatively on public health initiatives targeted to improve consumers knowledge and practices on consumption of safe pork [30]. Due to the low level of education, the general lack of knowledge on food legislation was expected. Improving the knowledge levels of consumers could advance food safety legislation awareness [31, 32]. In the South African context, awareness regarding hygiene practices and legal requirements may be enhanced by structures such as National and Provincial Departments of Health and of Agriculture, Food and Fisheries and the National Consumer Commission of South Africa who are mandated to ensure the welfare of consumers, which includes the implementation of relevant policies and strategies to ensure safe pork production in rural settings, such as the areas from this study.

Even though participants referred to cysts as "Amaqhakuva, Amaqhanqa or Intshulube" in IsiXhosa, it was of particular concern that almost half of the participants
(45.9\%) believed that pork with cysticercosis may not be harmful. This could be ascribed to the complexity of the life cycle of T. solium involving humans, pigs and environment; lack of knowledge and awareness of the public health importance of the parasite. Furthermore, since pork was bought from local butcheries there might be an element of trust that the pork was safe, without realising the possible consequences of consuming uninspected pork infected with T. solium cysts. This was similar to studies in Tanzania and Zimbabwe [33, 34], where it was reported that infected pork was purchased from unregistered fresh meat markets. A study conducted by Soji et al. [35], in South Africa, reported that consumers do not mind purchasing meat from formal or informal suppliers as long as it is affordable. This constitutes the need for consumer awareness campaigns by relevant authorities and other stakeholders. The development of schemes that would allow for gradual development of compliance would allow for interim registration and monitoring of butcheries on a regular basis to ensure safe meat products for human consumption (Powell et al., 2013).

The low percentage of consumers using freezers may be ascribed to the unaffordability thereof and the unavailability of electricity in most villages. This is an unfortunate situation as freezing of meat with $T$. solium 
cysts at $-5^{\circ} \mathrm{C}$ to $-24{ }^{\circ} \mathrm{C}$ for 1 to 4 days can inactivate $T$. solium cysts [36]. The South African red meat regulations prescribe temperatures of $-10^{\circ} \mathrm{C}$ for 10 days or $18^{\circ} \mathrm{C}$ for 3 days to inactivate the T. solium in pork meat [37]. It was proven that domestic freezers were capable of maintaining temperatures of $-20.3^{\circ} \mathrm{C}$, [38], which fell within the aforementioned temperature ranges and thus should have the capacity to deactivate $T$. solium cysts. However, the fact that most consumers preferred stewed pork was fortunate as this normally requires slow cooking for longer periods [39] wherein T. solium cysts can be inactivated when the pork reach an internal temperature of $65^{\circ} \mathrm{C}$ [40]. The other preparation methods, such as braai/barbeque, especially medium to rare are risky, as $T$. solium cysts may not be killed and consumers are exposed to infection [41].

\section{Conclusion}

This study confirmed that the majority of consumers from the study areas believed pork formed part of their diet as a source of protein, thus emphasising that rural pig farming would remain a source of livelihood for resource-poor farmers. Ensuring food safety, requires effective food safety systems that are vital to maintain consumer confidence and provide a sound regulatory foundation for domestic and international trade in food, which supports economic development [42]. This study revealed that pork consumers in the study areas have the likelihood of being exposed to pork infected with $T$. solium cysts, mainly due to eating uninspected pork derived from home-slaughtered pigs or buying of pork from unregistered sources and following unsafe cooking practices.

Given the importance of this parasite, awareness programmes for consumers should be initiated on the importance of consuming safe pork, and the zoonotic importance of $T$. solium since the parasite is endemic in these areas.

\section{Abbreviations}

CT: Computed tomography; NCC: Neurocysticercosis; OR Tambo: Oliver Reginald Tambo; SAS: Statistical analysis system; T. solium: Taenia solium

\section{Acknowledgements \\ The authors thank the Department of Agriculture, Land Reform and Rural Development (DALRRD) of South Africa for administrative support, Mr. Maruping Ntsatsi and staff of Veterinary Services of the Eastern Cape Province for field support, House of Traditional Leaders and Community Leaders for their support and finally the consumers who participated in the study.}

\section{Authors' contributions}

MIS was responsible for the study preparation, design, coordinating, data collection and analysis, and drafted manuscript. JLB and SM were responsible for conceptualising the idea, technical advice, guidance and editing of manuscript. All authors have read and approved the manuscript.

\section{Funding}

This research was funded through a grant provided by the Agricultural Research Council (ARC Project ID: 100148-Y5) of South Africa on behalf of the Departement of Agriculture, Land Reform and Rural Development (DALRRD). The funders had no role in the study design, data collection and analysis, decision to publish or preparaton of the manuscript.

\section{Availability of data and materials}

The data sets analysed during the current study are available from the corresponding author on reasonable request.

\section{Ethics approval and consent to participate}

Written approval for the study was obtained from the Tshwane University of Technology, with ethics clearance from the Faculty of Science Committees for Research Ethics (Reference number FCRE2016/06/001SCI) and the House of Traditional Leaders to conduct the study in their areas of jurisdiction. The latter required two presentations, which emphasised their roles in guiding communities regarding their customs and traditions and their consent to administer questionnaires to the community and use of their animals in the study. An information leaflet was provided to each prospective particpant regarding the study and written consent was obtained from all those included in the study. No minors (below 18 years of age) were included in the study.

\section{Consent for publication}

Not Applicable.

\section{Competing interests}

The authors declare that they have no competing interests.

\section{Author details}

'Department of Environmental Health, Tshwane University of Technology, Pretoria 0001, South Africa. ${ }^{2}$ School of Life Sciences, University of KwaZulu-Natal, Westville Campus, Durban, South Africa.

Received: 27 May 2019 Accepted: 31 January 2020

Published online: 06 February 2020

\section{References}

1. Carbas B, Cardoso L, Coelho AC. Investigation on the knowledge associated with foodborne diseases in consumers of northeastern Portugal. Food Control. 2013;30(1):54-7.

2. Goodman D, Watts M. Agrarian questions: global appetite, local metabolism: nature, culture, and industry in fin-de-siecle agro-food systems. In Globalising food. Routledge. 2013. p. 12-34.

3. Torgerson PR, et al. World Health Organization estimates of the global and regional disease burden of 11 foodborne parasitic diseases, 2010: a data synthesis. PLoS Med. 2015;12(12):e1001920.

4. Praet $\mathrm{N}$, et al. The disease burden of Taenia solium cysticercosis in Cameroon. PLoS Negl Trop Dis. 2009;3(3):e406.

5. FAO W. Multicriteria-based ranking for risk management of food-borne parasites. Rome: Food and Agriculture Organization; 2014.

6. Carabin $\mathrm{H}$, et al. Estimation of the cost of Taenia solium cysticercosis in eastern Cape Province, South Africa. Tropical Med Int Health. 2006;11(6): 906-16.

7. Schantz PM. Progress in diagnosis, treatment and elimination of echinococcosis and cysticercosis. Parasitol Int. 2006;55:S7-S13.

8. Gabriël S, et al. Control of Taenia solium taeniasis/cysticercosis: the best way forward for sub-Saharan Africa? Acta Trop. 2017;165:252-60.

9. Krecek $\mathrm{R}$, et al. Prevalence of Taenia solium cysticercosis in swine from a community-based study in 21 villages of the eastern Cape Province, South Africa. Vet Parasitol. 2008;154(1-2):38-47.

10. Phiri IK, et al. The emergence of Taenia solium cysticercosis in eastern and southern Africa as a serious agricultural problem and public health risk. Acta Trop. 2003;87(1):13-23.

11. Ocana GS, et al. Neurocysticercosis in patients presenting with epilepsy at St Elizabeth's hospital, Lusikisiki. SAMJ: South African Med J. 2009;99(8):588-91.

12. Krecek RC, et al. Risk factors of porcine cysticercosis in the eastern Cape Province, South Africa. PLoS One. 2012;7(5):e37718.

13. Sithole MI, Bekker JL, Mukaratirwa S. Pig husbandry and health practices of farmers in selected Taenia solium endemic rural villages of two districts in the eastern Cape Province of South Africa. Int J Vet Sci. 2019;8(4):235-42.

14. Lightowlers $M$, et al. Sensitivity of partial carcass dissection for assessment of porcine cysticercosis at necropsy. Int J Parasitol. 2015;45(13):815-8. 
15. Lightowlers $\mathrm{M}$, et al. Monitoring the outcomes of interventions against Taenia solium: options and suggestions. Parasite Immunol. 2016;38(3):158-69.

16. Sithole $\mathrm{Ml}$, et al. Ineffectiveness of meat inspection in the detection of Taenia solium cysticerci in pigs slaughtered at two abattoirs in the eastern Cape Province of South Africa. Veterinary Parasitol. 2019;17:100299.

17. Krecek $R$, et al. Questionnaire results from a community-based project on porcine cysticercosis in the eastern Cape Province of South Africa. Southeast Asian J Trop Med Pub Health. 2004;35:271-4.

18. Snedecor GW, Cochran WG. Statistical methods. 8th ed. Ames: Iowa State Univ. Press lowa; 1989

19. Wicklin R. Statistical programming with SAS/IML software. SAS Institute. 2010.

20. Hauschildt V, Schulze-Ehlersb B. An empirical investigation into the adoption of green procurement practices in the German food service industry. Int Food Agribusiness Manag Rev. 2014;17(3):1.

21. Sennott C, Mojola SA. 'Behaving well': the transition to respectable womanhood in rural South Africa. Cult Health Sex. 2017:19(7):781-95.

22. Jevšnik $M$, Hlebec $V$, Raspor $P$. Consumers' awareness of food safety from shopping to eating. Food Control. 2008;19(8):737-45.

23. Peltzer K, Phaswana-Mafuya N. The symptom experience of people living with HIV and AIDS in the eastern cape, South Africa. BMC Health Serv Res. 2008;8(1):271.

24. Veary C, Manoto SN. Neurocysticercosis: a possible cause of epileptiform seizures in people residing in villages served by the Bethanie clinic in the north West Province of South Africa. J S Afr Vet Assoc. 2008:79(2):84-8.

25. SAQA, South African Qualifications Authority. 2007, SAQA.

26. Kekana MV. Socio-Economic Factors Influencing Market Participation of Horticultural Smallholder Farmers in the Alfred Nzo District. Tshwane University of Technology. 2017.

27. Muyambo F, Jordaan AJ, Bahta YT. Assessing social vulnerability to drought in South Africa: policy implication for drought risk reduction. Jàmbá: J Disast Risk Stud. 2017;9(1):1-7.

28. Banerjee A, et al. Why has unemployment risen in the new South Africa? Econ Transit. 2008;16(4):715-40.

29. Modisaotsile BM. The failing standard of basic education in South Africa. Policy brief. 2012;72:1-7.

30. Siro l, et al. Functional food. Product development, marketing and consumer acceptance-a review. Appetite. 2008:51(3):456-67.

31. Yapp C, Fairman R. Factors affecting food safety compliance within small and medium-sized enterprises: implications for regulatory and enforcement strategies. Food Control. 2006;17(1):42-51.

32. Thomson GR, Leyland TJ, Donaldson Al. De-boned beef - an example of a commodity for which specific standards could be developed to ensure an appropriate level of protection for international trade. Transbound Emerg Dis. 2009;56(1-2):9-17.

33. Mutambara J. Non regulatory constraints affecting pig industry in Zimbabwe. Online J Animal Feed Res. 2013;3(1):62-7.

34. Mkupasi E, Shonyela S. Assessment of risk factors for porcine cysticercosis transmission and animal welfare in selected villages in Nyasa, Tanzania. Tanzania Vet J. 2017;32(1):48-54.

35. Soji $Z$, et al. Relevance of the formal red meat classification system to the south African informal livestock sector. South African J Animal Sci. 2015; 45(3):263-77.

36. Franssen $F$, et al. Inactivation of parasite transmission stages: efficacy of treatments on food of animal origin. Trends Food Sci Technol. 2019:83:114-28.

37. South Africa, Meat Safety Act 40 of 2000, D.A.L.R.R.D. Department of Agriculture, Land Reform and Rural Development, Editor. DALRRD: Government Gazette. 2000

38. Biglia A, et al. Temperature and energy performance of domestic cold appliances in households in England. Int J Refrig. 2018;87:172-84.

39. Li Y, et al. Physicochemical and fatty acid characteristics of stewed pork as affected by cooking method and time. Int J Food Sci Technol. 2016;51(2):359-69.

40. Lesh EJ, Brady MF. Tapeworm (Taenia Solium, Taenia Saginata, Diphyllobothrium, Cysticercosis, Neurocysticercosis), in StatPearls [Internet] StatPearls Publishing. 2019.

41. Roesel K, Grace D. Food safety and informal markets: Animal products in sub-Saharan Africa. Routledge. 2014

42. Ayalew $H$, Birhanu A, Asrade B. Review on food safety system: Ethiopian perspective. Afr J Food Sci. 2013;7(12):431-40.

\section{Publisher's Note}

Springer Nature remains neutral with regard to jurisdictional claims in published maps and institutional affiliations.
Ready to submit your research? Choose BMC and benefit from:

- fast, convenient online submission

- thorough peer review by experienced researchers in your field

- rapid publication on acceptance

- support for research data, including large and complex data types

- gold Open Access which fosters wider collaboration and increased citations

- maximum visibility for your research: over $100 \mathrm{M}$ website views per year

At BMC, research is always in progress.

Learn more biomedcentral.com/submissions 